OPEN ACCESS

Edited by:

Feng Guan,

Northwest University, China

Reviewed by:

Xiang Li,

Northwest University, China

Ning Shi,

University of Georgia, United States

${ }^{*}$ Correspondence:

Shiliang Wu

wushiliang@suda.edu.cn

Shaohua Wei

Shaohuawei2010@sina.com

tThese authors have contributed equally to this work.

Specialty section:

This article was submitted to Clinical and Translational Physiology, a section of the journal

Frontiers in Physiology

Received: 30 September 2017 Accepted: 02 May 2018

Published: 23 May 2018

Citation:

Jiang Z, Zhang H, Liu C, Yin J,

Tong S, LV J, Wei S and Wu S (2018) $\beta 3$ GnT8 Promotes Colorectal

Cancer Cells Invasion via CD147/MMP2/Galectin3 Axis.

Front. Physiol. 9:588. doi: 10.3389/fphys.2018.00588

\section{B3GnT8 Promotes Colorectal Cancer Cells Invasion via CD147/MMP2/Galectin3 Axis}

\author{
Zhi Jiang ${ }^{1 t}$, Huan Zhang ${ }^{2,3 t}$, Chunliang Liu ${ }^{1,4}$, Jun Yin ${ }^{5}$, Shan Tong ${ }^{5}$, Junxing L $v^{1}$, \\ Shaohua Wei ${ }^{2 *}$ and Shiliang $\mathrm{Wu}^{1 *}$
}

${ }^{1}$ Department of Biochemistry and Molecular Biology, School of Medicine, Soochow University, Suzhou, China, ${ }^{2}$ Department of General Surgery, The Second Affiliated Hospital of Soochow University, Suzhou, China, ${ }^{3}$ First People's Hospital of Changshu City, Changshu Hospital Affiliated to Soochow University, Changshu, China, ${ }^{4}$ Jiangsu Institute of Hematology, The First Affiliated Hospital of Soochow University, Suzhou, China, ${ }^{5}$ Department of General Surgery, The First Affiliated Hospital of Soochow University, Suzhou, China

$\beta 1,3-N$-acetylglucosaminyltransferase ( $\beta 3 G n T 8$ ) and $\beta 3 G n T 2$ are key enzymes that catalyzes the formation of polylactosamine glycan structures by transferring GlcNAc to tetra-antennary $\beta 1$-6-branched $N$-glycan and it also has an important effect on the progression of various types of human cancer. They have been reported to participate in tumor invasion and metastasis by regulating the expression of matrix metalloproteinases (MMPs), CD147, and polylactosamine. However, whether B3GnT8 and $\beta 3 G$ nT2 play a role in colorectal cancer and, if so, the underlying mechanisms remain unclear. In our study, we detected the expression of $\beta 3 G n T 8, C D 147$, MMP2, and galectin3 by immunohistochemistry on 90 paraffin-embedded slices. And $\beta 3 G n T 8$, CD147, MMP2, and galectin3 were over-expressed in colorectal cancer tissues. We found that overexpression of $\beta 3 G$ nT8 and $\beta 3 G n T 2$ promoted invasion of colorectal cancer cells, whereas knockdown of $\beta 3 \mathrm{GnT} 8$ and $\beta 3 \mathrm{GnT} 2$ inhibited the invasive activity. Mechanistically, $\beta 3 G$ nT8 and $\beta 3 G n T 2$ regulated the expression of HG-CD147 and the level of polylactosamines in colorectal cancer cells. Together, these results illustrate that the novel role and the molecular mechanism of $\beta 3 \mathrm{GnT} 8$ and $\beta 3 \mathrm{GnT2}$ in promotion of colorectal cancer invasion. These results suggest that the potential use of $\beta 3 \mathrm{GnT} 8$ as a tumor target for the therapy of colorectal cancer.

Keywords: $\beta 3 G$ nT8, polylactosamine, cell invasion, colorectal cancer, glycosylation

\section{INTRODUCTION}

Glycans in glycoconjugates including glycoproteins and glycolipids participate in a number of important biological events, including cell-cell interactions, inflammation, and tumor progression (Fuster and Esko, 2005). Poly- $N$-acetyllactosamine (PolyLacNAc), an important glycan structure containing repeats of the $N$-acetyllactosamine (LacNAc) unit (Gal1-4 GlcNAc1-3) $n$, is a fundamental structure of glycans carried on $N$ - or $O$-glycans, and is synthesized by $\beta-1,3-N$ acetylglucosaminyltransferase family ( $\beta 3 \mathrm{GnT}$ ) (Ishida et al., 2005). The $\beta 3 \mathrm{GnT}$ family includes of eight members, $\beta 3 \mathrm{GnT} 1$ to $\beta 3 \mathrm{GnT} 8$, which have been identified on the basis of structural similarity to the $\beta 1,3$-glycosyltransferase conserved motif sequence (Togayachi et al., 2010). When 
$\beta 3 \mathrm{GnT} 8$ was first cloned, it was named $\beta 3 \mathrm{GalT} 7$ and mapped to chromosome 19q13.2 by our laboratory (Huang et al., 2004). $\beta 3 \mathrm{GalT7}$ was renamed $\beta 3 \mathrm{GnT} 8$ on the basis of subsequent enzymatic study (Ishida et al., 2005). Previous studies have reported that $\beta 3 \mathrm{GnT} 2$ and $\beta 3 \mathrm{GnT} 8$ are mainly polylactosamine synthases, and suggested $\beta 3 \mathrm{GnT} 8$ worked as a coordinator with $\beta 3 \mathrm{GnT} 2$ to elongate the polylactosamine chain of multistranded $N$-glycans (Seko and Yamashita, 2005). And the expression of polylactosamine chains was increased by activating intrinsic $\beta 3 \mathrm{GnT} 2$ activity enhanced by upregulation of $\beta 3 \mathrm{GnT} 8$ in differentiated HL-60 cells (Seko and Yamashita, 2008). Therefore, $\beta 3 \mathrm{GnT} 8$ may have an important role in the regulation of the synthesis of polylactosamine.

CD147 is also known as extracellular matrix metalloproteinase inducer (EMMPRIN), which is a target glycoprotein of $\beta 3 \mathrm{GnT}$. And the expression of CD147 was at high levels on many human tumor cells (Ellis et al., 1989; Polette et al., 1997). CD147 has two forms, low glycosylated (LG)-CD147 $(\sim 32 \mathrm{kDa})$ form and high glycosylated (HG)-CD147 form $(\sim 40-$ $60 \mathrm{kDa}$ ). During the malignant transformation, the alteration of CD147 N-glycosylation has been demonstrated affected CD147 function (Bai et al., 2014). Previous studies have reported that CD147 deglycosylation induced by tunicamycin could inhibit the expression and secretion of matrix metalloproteinases (MMPs) (Sun and Hemler, 2001). The high polylactosamine content resulted in the elevated the expression of $\mathrm{HG}$ CD147, and CD147 which is a major carrier of $\beta 1,6$ branched polylactosamines was up-regulated on cancer cells and promoted tumor progression (Tang et al., 2004). Blocking CD147 or CD147-knockdown could induce cell apoptosis of colorectal cancer cells and delayed tumor growth (Baba et al., 2008; Ismail et al., 2016), which suggested targeting CD147 could be used as a potential strategy for colorectal cancer therapy.

Previously studies have reported that galectin-3 was a substrate for MMPs, and was cleaved between Ala62-Tyr63 by active MMP-2 and MMP-9 to form a $22 \mathrm{kDa}$ band (Ochieng et al., 1994; Nangia-Makker et al., 2007). PolyLacNAc was the most preferred ligands for galectin-3 (Sparrow et al., 1987). For example, LAMP1 carries significantly higher levels of PolyLacNAc, and has high affinity ligands for galectin-3 on tumor cell surface (Krishnan et al., 2005).

In previous study of our group, we have found that the positive relationship between $\beta 3 \mathrm{GnT} 8$ expression and HGCD147 in the colorectal cancer cell lines, and the level of $\beta 3 \mathrm{GnT}$ 8 was positive correlation with metastatic potential of colorectal cancer cell lines (Ni et al., 2014). Based on our previous study, we next further investigated the role and mechanism of $\beta 3 \mathrm{GnT} 8$ in colorectal cancer. In the current study, we detected the expression of $\beta 3 \mathrm{GnT} 8, \mathrm{CD} 147$, galectin3, and MMP2 in human colorectal cancer tissues and its adjacent paracancer tissues. We overexpressed and knocked down of $\beta 3 \mathrm{GnT} 8$ in colorectal cancer cell lines to dissect the effect of $\beta 3 \mathrm{GnT} 8$ on colorectal cancer cells invasion. Moreover, we further elucidated the role of $\beta 3 \mathrm{GnT} 8$ in regulation of polylactosamines synthesis which related with MMPs and galectin-3 expression.

\section{MATERIALS AND METHODS}

\section{Cell Culture and Cell Transfection}

The human CRC cell lines SW620, LS174T, and LoVo were cultured in RPMI-1640 (Gibco, Life Technologies) supplemented with $10 \%$ inactivated fetal bovine serum (Gibco, Life Technologies). All cell lines were cultured in a humidified atmosphere with $5 \% \quad \mathrm{CO}_{2}$ at $37^{\circ} \mathrm{C}$. The pEX-2-C1 (Mock), pEX-2- $\beta 3 \mathrm{GnT} 8$, and pEX-2- $\beta 3 \mathrm{GnT} 2$ plasmids were constructed as previously described (Liu et al., 2014). The pSilenCircle-negative control (NC), pSilenCircle-

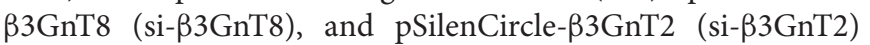
plasmids was established by GenePharma (Suzhou, China). Cells were collected $48 \mathrm{~h}$ for assays after transfection with Lipofectamine 2000 reagent (Invitrogen, Carlsbad, CA, United States).

\section{Immunohistochemistry (IHC) Staining}

Tissue microarray slides were obtained from Outdo Biotech (Shanghai, China), which contained 90 pairs of adjacent paracancer tissues and colorectal cancer tissues. The slides were stained with primary antibodies against $\beta 3 \mathrm{GnT}$, CD147 (Santa Cruz Biotechnology, Dallas, TX, United States), galectin3 (Abcam, Cambridge, MA, United States), MMP-2 (Abcam), ß3GnT2 (Santa Cruz Biotechnology), and HRP-conjugated antirabbit IgG, or anti-mouse IgG secondary antibody (Abcam). The protein expression was detected by DAB horseradish peroxidase color development kit (Beyotime, Haimen, China). The slides were evaluated by the staining intensity and positive cells percentage as follows: staining intensity, 0(no), 1(weak), 2(moderate), 3(strong), and positive cells percentage, $0(<1 \%)$, $1(1-33 \%), 2(34-66 \%), 3(67-100 \%)$. The final grade of target protein expression was calculated by plus the score of staining intensity and the score of positive cells percentage: $0(0), 1+(1-$ $2), 2+(3-4)$, and $3+(5-6)$. The expression scores of $\beta 3 \mathrm{GnT} 8$, CD147, galectin3 and MMP-2 were provided in Supplementary Data Sheet 1 (Supplementary Tables 1-4).

\section{Quantitative Real-Time PCR Analysis}

The mRNA of CRC cell lines was isolated and reversetranscripted to cDNAs by the reverse transcription kit (Invitrogen). Then the cDNAs was used for quantitative PCR analysis using SYBR Green Master Mix Kit (Toyobo, Osaka, Japan) and an ABI detection system (Applied Biosystems, Foster City, CA, United States). The PCR primers were as follows: GAPDH forward, 5'-AGAAGGCTGGGGCTCATT TG-3' and reverse, 5'-AGGGGCCATCCACAGTCTTC-3'; 33 GnT8 forward, 5'-GTCGCTACAGTGACCTGCTG-3' and reverse, $\quad 5^{\prime}$-GTCTTTGAGCGTCTGGTTGA-3'; $\quad$; 3 GnT2 forward, 5'-ATACTGGAACCGAGAGCAAG-3' and reverse, 5'-TCAGGTTCGCAGTAGTTCAG-3'; CD147 forward, 5'-AC CGTAGAAGACCTTGGCTC-3' and reverse, 5'-CGTCGGAG TCCACCTTGAAC-3'; MMP2 forward, 5'-TATGGCTTCTGC CCTGAGAC- $3^{\prime}$ and reverse, 5'-CACACCACA TCTTTCCG TCA-3'; Galectin3 forward, 5'-GTGCCTCGCATGCTGATA AC-3' and reverse, 5'-ACACATGTAAGTGCAAACAATGA 
TABLE 1 | Relationship between $\beta 3 G$ nT8, CD147, galectin3, MMP2 expression and clinicopathological features of colorectal cancer patients.

\begin{tabular}{|c|c|c|c|c|c|c|c|c|c|c|c|c|c|}
\hline \multirow[t]{2}{*}{ Clinico-pathological features } & \multirow[t]{2}{*}{$n$} & \multicolumn{2}{|c|}{$\beta 3 \mathrm{GnT} 8$} & \multirow[t]{2}{*}{$\boldsymbol{P}$} & \multicolumn{2}{|c|}{ CD147 } & \multirow[t]{2}{*}{$P$} & \multicolumn{2}{|c|}{ Galectin3 } & \multirow[t]{2}{*}{$\boldsymbol{P}$} & \multicolumn{2}{|c|}{ MMP2 } & \multirow[t]{2}{*}{$P$} \\
\hline & & High & Low & & High & Low & & High & Low & & High & Low & \\
\hline \multicolumn{14}{|l|}{ Age } \\
\hline$<60$ & 16 & 15 & 1 & 0.622 & 15 & 1 & 0.031 & 6 & 10 & 0.27 & 5 & 11 & 0.927 \\
\hline$\geq 60$ & 74 & 64 & 10 & & 74 & 0 & & 39 & 35 & & 24 & 50 & \\
\hline \multicolumn{14}{|l|}{ Gender } \\
\hline Male & 45 & 41 & 4 & 0.334 & 44 & 1 & 0.315 & 25 & 20 & 0.292 & 14 & 31 & 0.822 \\
\hline Female & 45 & 38 & 7 & & 45 & 0 & & 20 & 25 & & 15 & 30 & \\
\hline \multicolumn{14}{|l|}{ Tumor size } \\
\hline$<5 \mathrm{~cm}$ & 34 & 31 & 3 & 0.443 & 33 & 1 & 0.197 & 20 & 14 & 0.192 & 10 & 24 & 0.657 \\
\hline$\geq 5 \mathrm{~cm}$ & 56 & 48 & 8 & & 56 & 0 & & 25 & 31 & & 19 & 37 & \\
\hline \multicolumn{14}{|l|}{ 7-year survival } \\
\hline Yes & 47 & 42 & 5 & 0.631 & 47 & 0 & 0.293 & 27 & 20 & 0.14 & 15 & 32 & 0.948 \\
\hline No & 43 & 37 & 6 & & 42 & 1 & & 18 & 25 & & 14 & 29 & \\
\hline \multicolumn{14}{|l|}{ TNM stage } \\
\hline $1+11$ & 55 & 47 & 8 & 0.399 & 55 & 0 & 0.207 & 30 & 25 & 0.28 & 19 & 36 & 0.544 \\
\hline III+IV & 35 & 32 & 3 & & 34 & 1 & & 15 & 20 & & 10 & 25 & \\
\hline \multicolumn{14}{|l|}{ Lymph node metastasis } \\
\hline Positive & 36 & 32 & 4 & 0.793 & 35 & 1 & 0.218 & 15 & 21 & 0.197 & 11 & 25 & 0.782 \\
\hline Negative & 54 & 47 & 7 & & 54 & 0 & & 30 & 24 & & 18 & 36 & \\
\hline
\end{tabular}

\section{A \\ B3GnT8 \\ B \\ CD147 \\ C \\ Galectin3 \\ D \\ MMP2}
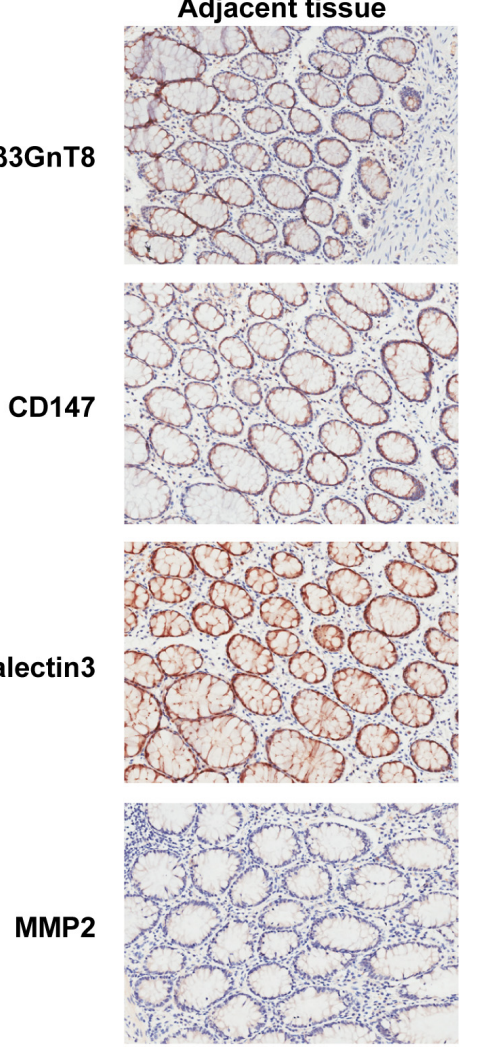
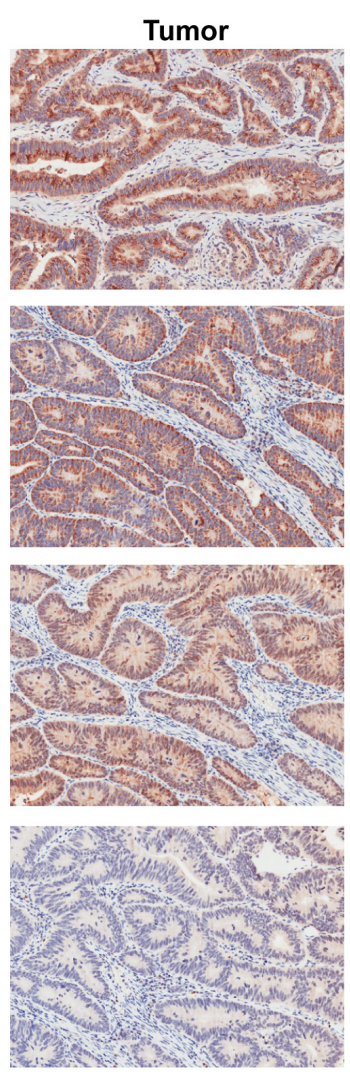
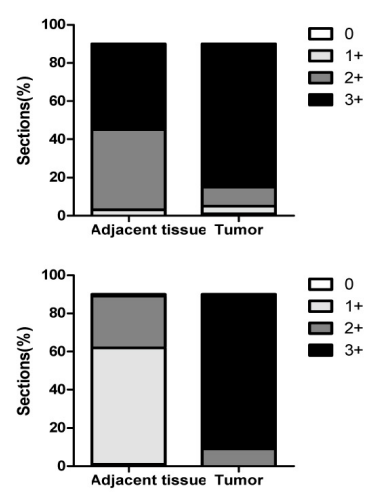

믐 ${ }^{1+}$

믈
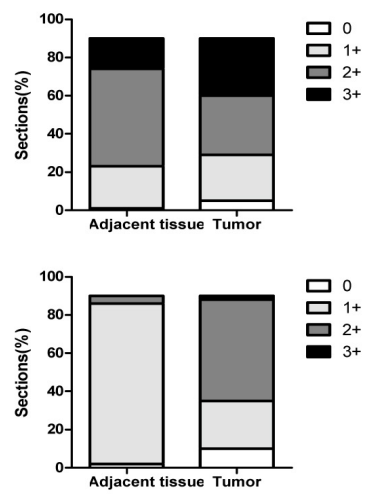

FIGURE 1 | $\beta 3$ GnT8, CD147, galectin3, and MMP2 expressions in colorectal cancer tissues. (A-D) Immunohistochemical staining for the expression of $\beta 3 G$ nT8, CD147, galectin3, and MMP2 in adjacent paracancer tissues and colorectal cancer tissues. The summary data of immunohistochemical staining score was evaluated by staining intensity and positive cells percentage. Magnification, $\times 200$. 
CT- $3^{\prime}$. The relative expression data were calculated by $2^{-\Delta \Delta C_{t}}$ method using GAPDH as internal control.

\section{Western Blot Analysis}

Total proteins were extracted from CRC cell lines using RIPA lysis buffer containing $1 \mathrm{mM}$ PMSF (Pierce, Rockford, IL, United States) and quantified by BCA Protein Assay Kit (Pierce, Rockford, IL, United States). Proteins were separated on SDS-PAGE and transferred to NC membranes (EMD Millipore, Billerica, MA, United States). After blocking with 5\% skimmed milk, the membranes were incubated with different antibodies at $4^{\circ} \mathrm{C}$ overnight. Following three washes in TBS containing Tween-20, the membranes were incubated at room temperature for $2 \mathrm{~h}$ with the secondary antibody. The protein bands were detected by ECL western blot kit (GE Healthcare Life Sciences, Shanghai, China). The primary antibodies used were as follows: anti- $\beta 3 \mathrm{GnT} 8$ (produced by our laboratory) (Jiang et al., 2010), anti-CD147, anti- $\beta 3 \mathrm{GnT} 2$, anti-galectin3, anti-GAPDH (Abcam), or $\beta$-actin (Abcam).

\section{Wound Healing Assay}

SW620 cells $\left(4 \times 10^{5}\right.$ cells per well $)$ were seeded into a 12 -well plate and incubated overnight. A wound was created by scraping monolayer cells with a sterile pipette tip. Cell motility was examined using a light microscope. The photographs were taken immediately $(0)$ and $24 \mathrm{~h}$ after wounding. The resulting experiments were analyzed by the ImageJ software (National
Institutes of Health, Bethesda, MD, United States). The area of each wound was calculated at each time point.

\section{Flow Cytometric Analysis}

The polylactosamine structures of cell-surface glycoproteins were detected using biotin-labeled Solanum lycopersicum (tomato) agglutinin lectin (LEA; Sigma-Aldrich; Merck KGaA, Darmstadt, Germany). Cells were collected, washed three times with PBS and adjusted to $3 \times 10^{6}$ cells $/ \mathrm{ml}$. Then the cells were stained with $10 \mu \mathrm{g} / \mathrm{ml} \mathrm{LEA}$ at $37^{\circ} \mathrm{C}$ for $1 \mathrm{~h}$. Washed the stained cells three times with PBST (PBS containing 0.05\% Tween-20) and then stained cells with $10 \mu \mathrm{g} / \mathrm{ml}$ PE-conjugated streptavidin (SigmaAldrich; Merck KGaA) at $37^{\circ} \mathrm{C}$ for $1 \mathrm{~h}$. The cells were washed and measured for the fluorescence intensity by BD Calibur flow cytometer. The data was analyzed with Cell Quest software (BD Biosciences, United States).

\section{MALDI-TOF/TOF-MS Analysis}

Total proteins were extracted from CRC cell lines and quantified by BCA Protein Assay Kit. Proteins (2 mg) were used for MALDI-TOF/TOF-MS analysis. The assay procedure was performed as described previously (Yang et al., 2015). $N$-glycans were analyzed according to method reported (Ceroni et al., 2008).

\section{Statistical Analysis}

Data are presented as means \pm standard deviation (SD). The statistical analysis was done by Student's $t$-test using SPSS

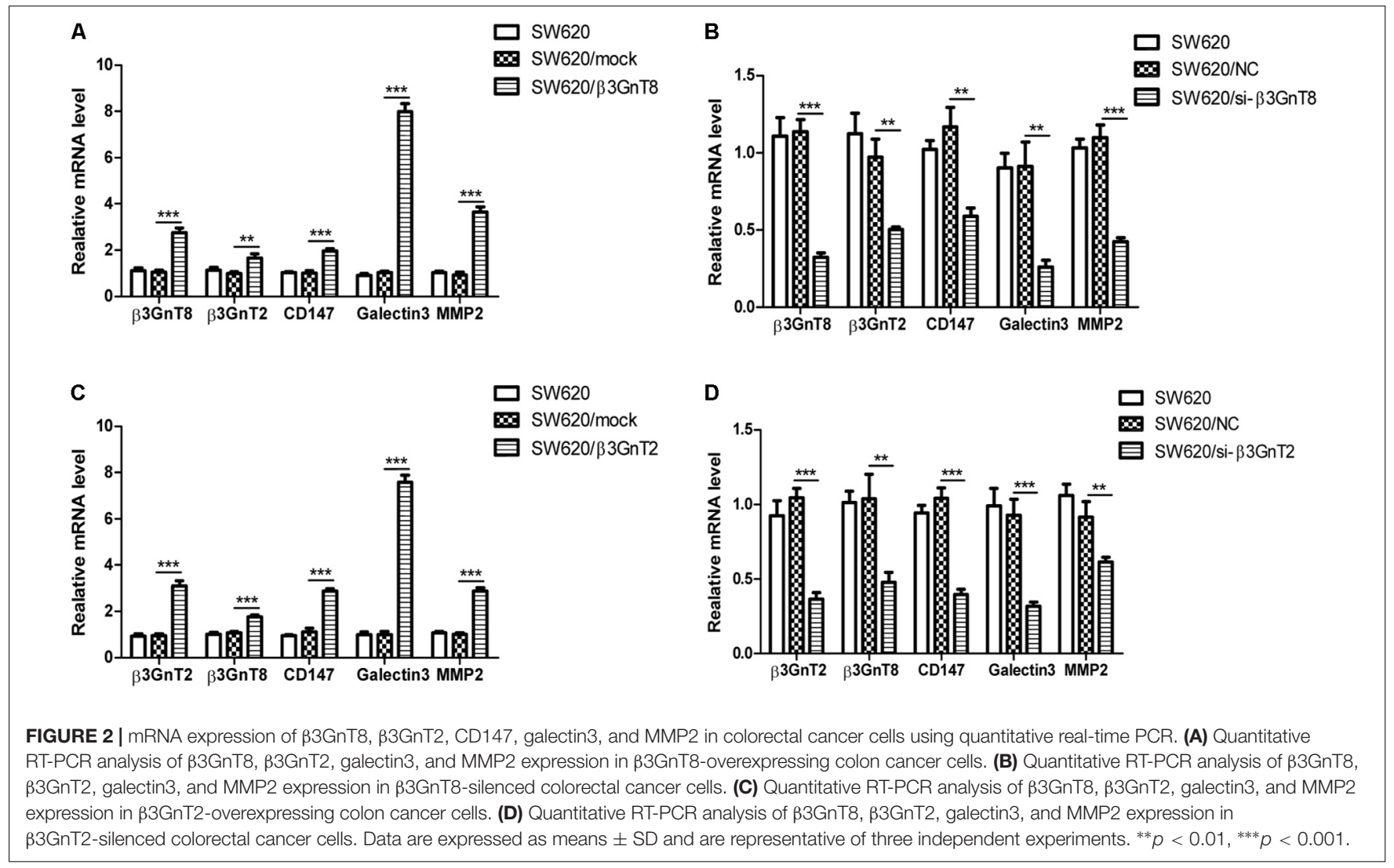


software (version 22.0, SPSS Inc.). For all analysis, $p$ less than $0.05\left(^{*}\right)$ was considered to indicate a statistically significant difference, and $p$-value was indicated as $* p<0.05,{ }^{* *} p<0.01$, and ${ }^{* * *} p<0.001$.

\section{RESULTS}

\section{Expression of $\beta 3 G$ nT8 Is Increased in Human Colorectal Cancer Tissues}

To investigate the effect and correlation of $\beta 3 \mathrm{GnT} 8$ with the progression of colorectal cancer, we used immunohistochemical staining method to detect the expression of $\beta 3 \mathrm{GnT} 8$ in 90 pairs of colorectal cancer tissues and its adjacent paracancer tissues (Table 1). We found that the expression level of $\beta 3 \mathrm{GnT} 8$ was higher in colorectal cancer tissues than in adjacent paracancer tissues (Figure 1A). Consistent with $\beta 3 \mathrm{GnT}$, the expression of CD147, galectin3, and MMP2 were also up-regulated in colorectal cancer tissues (Figures 1B-D). These results suggested that $\beta 3 \mathrm{GnT} 8$ expression was positively correlated with CD147, galectin3, and MMP2 expression in colorectal cancer tissues. However, the expression of $\beta 3 \mathrm{GnT} 2$ was decreased in colorectal cancer tissues (Supplementary Figure 1), which was contrary to the $\beta 3 \mathrm{GnT} 8$ expression. Then the relationship between $\beta 3 \mathrm{GnT}$, CD147, galectin3, MMP2 expression and clinico-pathological features of colorectal cancer was analyzed. However, the expression of $\beta 3 \mathrm{GnT} 8 \mathrm{CD} 147$, galectin3, and MMP2 have no correlation with any clinic-pathological factors (Table 1).

\section{$\beta 3 G n T 8$ and $\beta 3 G n T 2$ Promotes Colorectal Cancer Cell Invasion in Vitro}

Based on the previous study of our group ( $\mathrm{Ni}$ et al., 2014), we choose the SW620 cell line to explore the role of $\beta 3 \mathrm{GnT} 8$ and $\beta 3 \mathrm{GnT} 2$. The $\beta 3 \mathrm{GnT} 8$ over-expression cells and $\beta 3 \mathrm{GnT} 8$ knockdown cells were successfully constructed (Figures 2A,B, 3A,B). We also constructed $\beta 3 \mathrm{GnT} 2$ overexpression cells and $\beta 3 \mathrm{GnT} 2$ knockdown cells (Figures 2C,D, 3C,D). Then we used these cells to perform wound healing assay

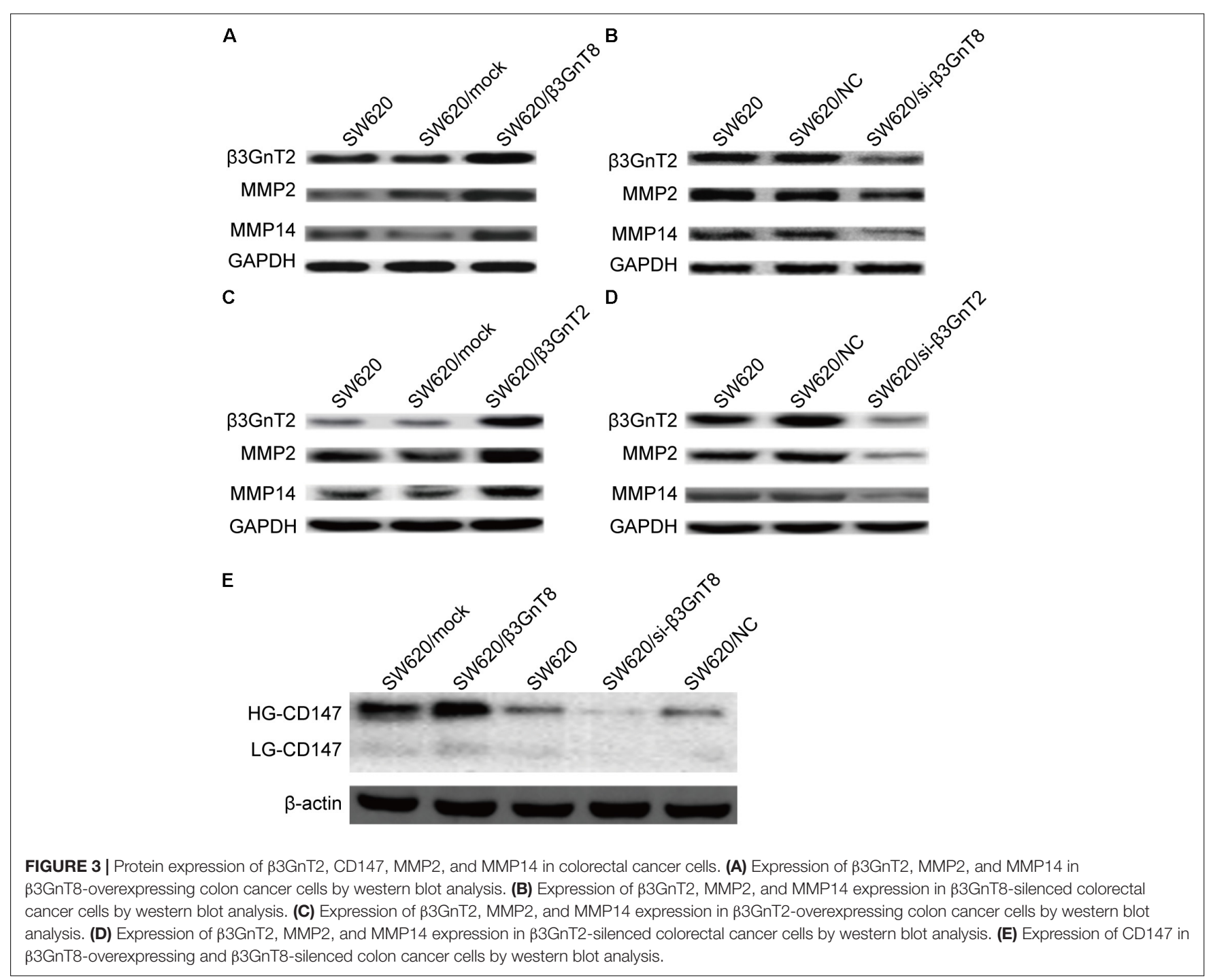


to deliberated the effect of $\beta 3 \mathrm{GnT} 8$ on the invasion colorectal cancer cells. The $\beta 3 \mathrm{GnT}$ 8-overexpression promoted cell invasion and $\beta 3 \mathrm{GnT} 8$-knockdown suppressed cell invasion dramatically after $24 \mathrm{~h}$ incubation (Figure 4A). We also found the same results in the cells overexpression of $\beta 3 \mathrm{GnT} 2$ or knockdown of $\beta 3 \mathrm{GnT} 2$ (Figure 4B). These results suggested that $\beta 3 \mathrm{GnT} 2$ and $\beta 3 \mathrm{GnT} 8$ were sufficient to promote colorectal cancer invasion in vitro, respectively.

\section{B3GnT8 Promotes Cell Invasion via CD147, Galectin 3, and MMPs Expression}

We investigated whether $\beta 3 \mathrm{GnT} 8$ could affect the expression of CD147, galectin 3, and MMPs. $\beta 3 \mathrm{GnT} 8$ overexpression significantly increased the mRNA expression of CD147, galectin 3, and MMPs (Figures 2A,B). As expected that expression of $\beta 3 \mathrm{GnT} 2$ also significantly elevated the mRNA levels of CD147, galectin 3, and MMPs in colorectal cancer cells in comparison with the controls (Figures 2C,D). The same results were shown in Supplementary Figure 2 for other colorectal cancer cell lines. Then we analyzed the protein levels of those tumor-related genes, and found that both $\beta 3 \mathrm{GnT} 8$ and $\beta 3 \mathrm{GnT} 2$ could markedly elevate MMP2 and MMP14 expression (Figure 3). Collectively, these results indicated that $\beta 3 \mathrm{GnT} 8$ promoted cell invasion via enhancing the expression of galectin 3 and MMPs.

\section{ß3GnT8 Promotes Cell Invasion via Enhancing HG-CD147 Glycosylation}

We detected the CD147 glycosylation in colorectal cancer cells by western blot analysis. And we found that $\beta 3 \mathrm{GnT}$-overexpression significantly increased the expression of HG-CD147, while B3GnT8-knockdown decreased the levels of HG-CD147 in colorectal cancer cells (Figure 3E). However, $\beta 3 \mathrm{GnT}$ 8 almost has no effect on the expression of LG-CD147. These results suggested $\beta 3 \mathrm{GnT}$ 8 could regulation the function of CD147. Therefore, the heterogeneous $\mathrm{N}$-glycosylated forms of CD147 may be regulated by $\beta 3 \mathrm{GnT} 8$ in colorectal cancer cells. Therefore, $\beta 3 \mathrm{GnT} 8$ promoted the expression of MMP2 though enhancing the HG-CD147 glycosylation.

\section{B3GnT8 Regulates Polylactosamines Expression in Colorectal Cancer Cells}

The polylactosamine chains on $N$-linked $\beta 1,6$-branch affect the development of cancer (Huang et al., 2013), we further detected the expression of total polylactosamines in SW620 cells using flow cytometric analysis. We found that of $\beta 3 \mathrm{GnT}$-overexpression upregulated the polylactosamines expression, while $\beta 3 \mathrm{GnT} 8$ knockdown down-regulated the polylactosamines expression in SW620 cells (Figures 5A,B). $\beta 3$ GnT2 performed the same result as $\beta 3 \mathrm{GnT}$ (Figures $\mathbf{5 A}, \mathbf{C}$ ). These results suggest that $\beta 3 \mathrm{GnT} 8$ and $\beta 3 \mathrm{GnT} 2$ have significant effects on the biosynthesis of

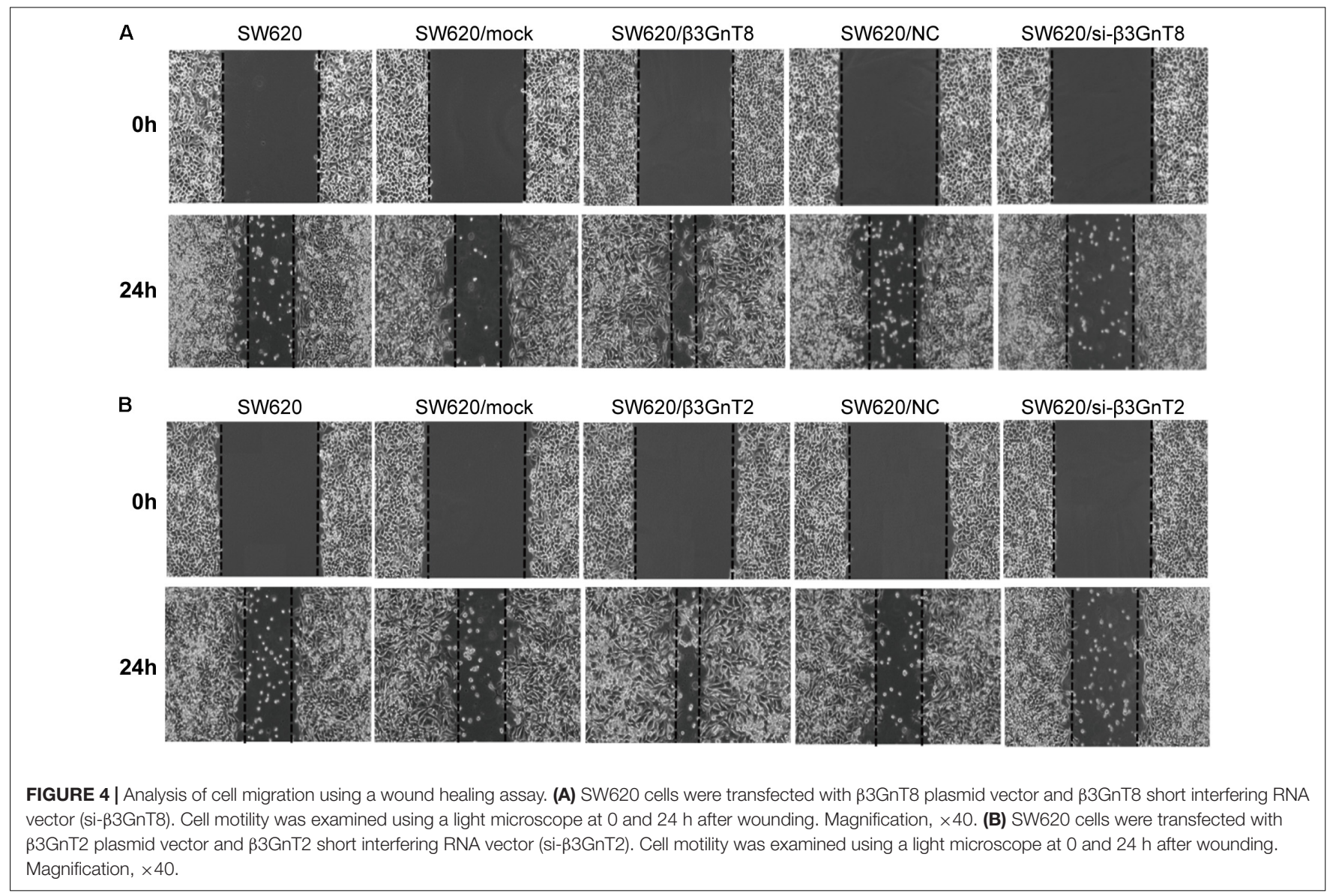




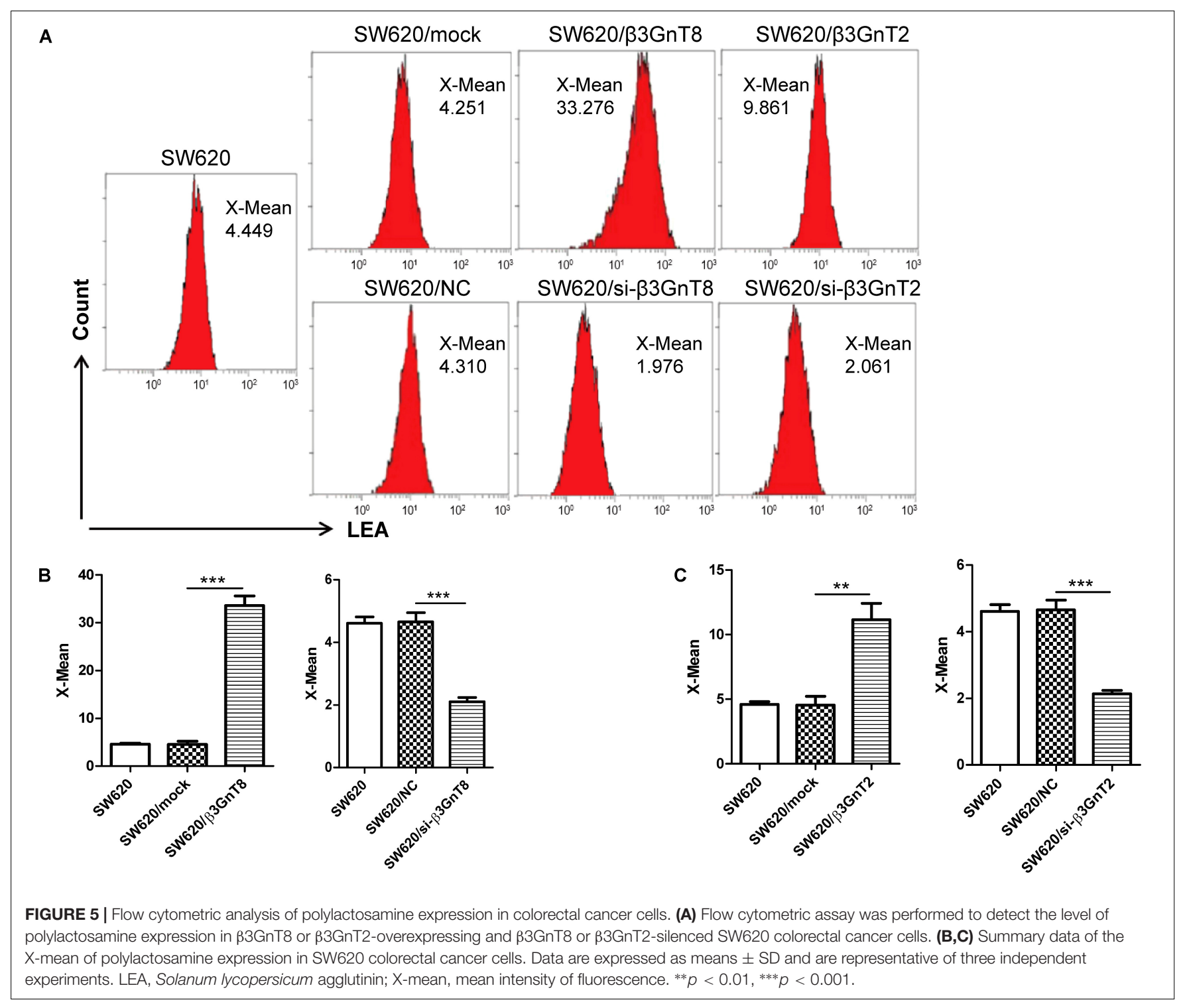

polylactosamine chain which affect the expression of MMPs and galectin3.

\section{B3GnT8 Changes $\mathbf{N}$-glycan Patterns in Colorectal Cancer Cells}

$N$-glycosylation patterns were aberrant in many cancers, suggesting that the cancer-associated $N$-glycans may be potential tumor biomarkers (Meany and Chan, 2011; Adamczyk et al., 2012). The total $N$-glycans in colorectal cancer cells were profiled by MALDI-TOF/TOF-MS analysis. We found that the number of $N$-glycan structures was 29 in LS174T/mock cells and 28 in LS174T/ $\beta 3$ GnT8 cells, but only 19 in LS174T/ $\beta 3$ GnT2 cells (Supplementary Figure 3). As shown in Supplementary Figure 4, the number of $\mathrm{N}$-glycan structures was 19 in LoVo/NC cells and 17 in LoVo/si- $\beta 3 \mathrm{GnT} 8$ cells, but 21 in LoVo/si- $\beta 3 \mathrm{GnT} 2$ cells. Overexpression of $\beta 3 \mathrm{GnT} 8$ and $\beta 3 \mathrm{GnT} 2$ only increased the percentage of high-mannose-type in LS174T cells (Table 2).
TABLE 2 | N-glycans types in colorectal cancer cell lines.

\begin{tabular}{|c|c|c|c|c|c|c|}
\hline \multirow[t]{3}{*}{ Glycan type } & \multicolumn{6}{|c|}{ Relative proportion (\%) } \\
\hline & \multicolumn{3}{|c|}{ LS174T } & \multicolumn{3}{|c|}{ LoVo } \\
\hline & Mock & $\beta 3 G n T 8$ & $\beta 3 \mathrm{GnT2}$ & NC & si- $\beta 3 \mathrm{GnT}$ 7 & si- $\beta 3$ GnT2 \\
\hline $\begin{array}{l}\text { High } \\
\text { mannose }\end{array}$ & $45.4 \%$ & $87.1 \%$ & $68.8 \%$ & $90.5 \%$ & $92.5 \%$ & $89.3 \%$ \\
\hline Complex & $32.6 \%$ & $10.5 \%$ & $26.2 \%$ & $7.8 \%$ & $5.0 \%$ & $8.9 \%$ \\
\hline Hybrid & $14.6 \%$ & $8.3 \%$ & $19.1 \%$ & $7.0 \%$ & $6.4 \%$ & $6.9 \%$ \\
\hline Bi-antennary & $25.7 \%$ & $7.6 \%$ & $20.8 \%$ & $6.4 \%$ & $4.2 \%$ & $7.6 \%$ \\
\hline $\begin{array}{l}\text { Tri- and Tetra- } \\
\text { antennary }\end{array}$ & $6.9 \%$ & $3.5 \%$ & $7.0 \%$ & $2.6 \%$ & $0.7 \%$ & $2.6 \%$ \\
\hline $\begin{array}{l}\text { Bisecting } \\
\text { GlcNAc }\end{array}$ & $15.7 \%$ & $6.3 \%$ & $17.3 \%$ & $6.4 \%$ & $4.2 \%$ & $6.3 \%$ \\
\hline Fucosylation & $43.2 \%$ & $16.1 \%$ & $36.5 \%$ & $17.0 \%$ & $11.2 \%$ & $18.0 \%$ \\
\hline Sialylation & $5.6 \%$ & $2.4 \%$ & $4.1 \%$ & $2.8 \%$ & $3.1 \%$ & $2.8 \%$ \\
\hline Lactose & $3.6 \%$ & $2.5 \%$ & $5.2 \%$ & $0.0 \%$ & $0.0 \%$ & $0.5 \%$ \\
\hline
\end{tabular}




\section{DISCUSSION}

Colorectal cancer is a leading cause of cancer-associated mortality (Siegel et al., 2017). Aberrant glycosylation involved in colorectal cancer progression (de Freitas Junior and Morgado-Diaz, 2016). Previous studies have reported that the $\beta 1,6$ branches of $N$-glycans are associated with the invasion and metastasis of colorectal cancer and an increase of $\beta 1,6$ branches on $\mathrm{N}$-glycans is commonly observed with malignant transforms. Characteristics of $\beta 1,6$-branched $N$-glycans are considered hallmarks of colorectal cancer progression (Ishida et al., 2005).

In present study, we showed that the expression of $\beta 3 \mathrm{GnT} 8$, CD147, galectin3, and MMP2 were significantly higher in colorectal cancer tissues, while the expression of $\beta 3 \mathrm{GnT} 2$ was decreased in cancer tissues. $\beta 3 \mathrm{GnT} 8$-overexpression promoted the invasion of colorectal cancer cells, while $\beta 3 \mathrm{GnT} 8$-knockdown suppressed the ability of cell invasion, these results suggested that $\beta 3 \mathrm{GnT} 8$ played an important role in the development of colorectal cancer. Our study also found that $\beta 3 \mathrm{GnT} 8$ can regulate the expression of $\beta 3 \mathrm{GnT} 2, \mathrm{CD} 147$, galectin3, and MMPs. We know that not only high expressions of MMPs and CD147 are associated with tumor invasion, but also high expression of tumoral galectin-3 was associated with tumor size and poor differentiation but negatively related to low E-cadherin expression (Huang et al., 2016). Our findings indicated that $\beta 3 \mathrm{GnT} 8$ could promote colorectal cancer invasion by enhancing the expression of MMPs, CD147, and galectin3. We also know that $\beta 3 \mathrm{GnT} 8$ and $\beta 3 \mathrm{GnT} 2$ can form a heterocomplex and the enzymatic activity is enhanced, this suggest that $\beta 3 \mathrm{GnT} 2$ and $\beta 3 \mathrm{GnT} 8$ may be cooperatively regulated the polylactosamine chains elongation (Seko and Yamashita, 2005). Previous study also suggested that upregulation of $\beta 3 \mathrm{GnT} 8$ could enhance $\beta 3 \mathrm{GnT} 2$ activity to increase the expression of polylactosamines in differentiated HL-60 cells (Seko and Yamashita, 2008).

$\beta 3 \mathrm{GnT} 8$ was expressed highly in gastric cancer and regulated the metastasis of gastric cancer cells via modulating the polylactosamines of CD147 (Shen et al., 2017). Our lab has also demonstrated that $\beta 3 \mathrm{GnT} 8$ may affect the signaling pathway of CD147 (Jiang et al., 2014). CD147 has a high expression on surface of tumor cells (Sameshima et al., 2000; Pan et al., 2012; Zhu et al., 2013). Also, CD147 has the high-glycosylated forms, and plays key roles in metastasis of tumors. The HG-CD147 could stimulate tumor cells to produce MMPs (Jiang et al., 2001). Therefore, we investigated whether $\beta 3 \mathrm{GnT} 8$ affect the glycosylation of CD147 in colorectal cancer cells. And we demonstrated that overexpression of $\beta 3 \mathrm{GnT} 8$ increased the expression of HG-CD147 in colorectal cancer cells, and knockdown of $\beta 3 \mathrm{GnT} 8$ reduced HG-CD147 expression, suggesting that $\beta 3 \mathrm{GnT} 8$ might regulate the expression of MMP2 through altering CD147 glycosylation in colorectal cancer. And our lab has also demonstrated that the polylactosamines level in CD147 was regulated by $\beta 3 \mathrm{GnT} 8$ via IP assay (Shen et al., 2017). These studies indicated $\beta 3 \mathrm{GnT} 8$ affect the tumor development through MMPs expression which could be regulated by CD147 glycosylation (Sameshima et al., 2000).

$\beta 3 \mathrm{GnT}$ 8 was reported participated in the regulation of polylactosamines synthesis on $\beta 1,6$-branched $N$-glycans
(Ishida et al., 2005; Seko and Yamashita, 2005). And global changes in protein glycosylation are associated with cancer (Kim et al., 2009). We found $\beta 3 \mathrm{GnT}$ - -overexpression increased and $\beta 3 \mathrm{GnT} 8$-knockdown reduced the expression of polylactosamines and glycopattern abundance in colorectal cancer cells, Moreover, the expression of MMPs and galectin3, which was regulated by polylactosamines, was also positively correlated with $\beta 3 \mathrm{GnT}$. Our results suggested that $\beta 3 \mathrm{GnT} 8$ could change CD147 glycosylation and global protein glycosylation.

Based on our previous study, we found $\beta 3 \mathrm{GnT} 8$ expression was increased in colorectal cancer tissues, and the $\beta 3 \mathrm{GnT} 8$ expression was positively correlated with CD147, galectin3, and MMP2 expression in colorectal cancer tissues and cell lines in this study. Therefore, $\beta 3 \mathrm{GnT} 8$ may promotes colorectal cancer invasion via enhancing the expression of MMPs, CD147, and galectin3. And we confirmed that $\beta 3 \mathrm{GnT} 8$ promoted the invasion of colorectal cancer cells through increasing the expression of HG-CD147. The expression of $\beta 3 \mathrm{GnT} 8$ and $\beta 3 \mathrm{GnT} 2$ was not positively correlated in clinical colorectal cancer tissues, while $\beta 3 \mathrm{GnT}$ 8 worked as a coordinator with $\beta 3 \mathrm{GnT} 2$ to regulate the expression of polylactosamine and MMPs in vitro. Our findings demonstrated that $\beta 3 \mathrm{GnT} 8$ plays an important role in the progression of colorectal cancer, suggesting that the potential use of $\beta 3 \mathrm{GnT} 8$ as a tumor target for the prevention of colorectal cancer invasion.

\section{ETHICS STATEMENT}

This study was approved by the ethics committee of the Soochow University. Informed consent was obtained from all patients in the study.

\section{AUTHOR CONTRIBUTIONS}

ZJ and SlW designed the study and wrote the manuscript. ZJ, HZ, ST, JL, and JY performed the experiments. ZJ, CL, and ShW performed the statistical analyses and critiqued the manuscript. All authors read and approved the final manuscript

\section{FUNDING}

This study was supported by grants from the National Natural Science Foundation of China (31400688 and 31170772).

\section{ACKNOWLEDGMENTS}

We thank for the help of Feng Guan professor from Northwest University in the analysis of MALDI-TOF/TOF-MS.

\section{SUPPLEMENTARY MATERIAL}

The Supplementary Material for this article can be found online at: https://www.frontiersin.org/articles/10.3389/fphys.2018. 00588/full\#supplementary-material 


\section{REFERENCES}

Adamczyk, B., Tharmalingam, T., and Rudd, P. M. (2012). Glycans as cancer biomarkers. Biochim. Biophys. Acta 1820, 1347-1353. doi: 10.1016/j.bbagen. 2011.12.001

Baba, M., Inoue, M., Itoh, K., and Nishizawa, Y. (2008). Blocking CD147 induces cell death in cancer cells through impairment of glycolytic energy metabolism. Biochem. Biophys. Res. Commun. 374, 111-116. doi: 10.1016/j.bbrc.2008.06.122

Bai, Y., Huang, W., Ma, L. T., Jiang, J. L., and Chen, Z. N. (2014). Importance of N-glycosylation on CD147 for its biological functions. Int. J. Mol. Sci. 15, 6356-6377. doi: 10.3390/ijms15046356

Ceroni, A., Maass, K., Geyer, H., Geyer, R., Dell, A., and Haslam, S. M. (2008). GlycoWorkbench: a tool for the computer-assisted annotation of mass spectra of glycans. J. Proteome Res. 7, 1650-1659. doi: 10.1021/pr7008252

de Freitas Junior, J. C., and Morgado-Diaz, J. A. (2016). The role of N-glycans in colorectal cancer progression: potential biomarkers and therapeutic applications. Oncotarget 7, 19395-19413. doi: 10.18632/oncotarget.6283

Ellis, S. M., Nabeshima, K., and Biswas, C. (1989). Monoclonal antibody preparation and purification of a tumor cell collagenase-stimulatory factor. Cancer Res. 49, 3385-3391.

Fuster, M. M., and Esko, J. D. (2005). The sweet and sour of cancer: glycans as novel therapeutic targets. Nat. Rev. Cancer 5, 526-542. doi: 10.1038/nrc1649

Huang, C., Zhou, J., Wu, S., Shan, Y., Teng, S., and Yu, L. (2004). Cloning and tissue distribution of the human B3GALT7 gene, a member of the beta1,3Glycosyltransferase family. Glycoconj. J. 21, 267-273. doi: 10.1023/B:GLYC. $0000045098.78968 .4 \mathrm{c}$

Huang, W., Luo, W. J., Zhu, P., Tang, J., Yu, X. L., Cui, H. Y., et al. (2013). Modulation of CD147-induced matrix metalloproteinase activity: role of CD147 N-glycosylation. Biochem. J. 449, 437-448. doi: 10.1042/BJ20120343

Huang, Z., Ai, Z., Li, N., Xi, H., Gao, X., Wang, F., et al. (2016). Over expression of galectin-3 associates with short-term poor prognosis in stage II colon cancer. Cancer Biomark. 17, 445-455. doi: 10.3233/CBM-160661

Ishida, H., Togayachi, A., Sakai, T., Iwai, T., Hiruma, T., Sato, T., et al. (2005). A novel beta1,3-N-acetylglucosaminyltransferase ( $\beta 3 \mathrm{Gn}-\mathrm{T} 8)$, which synthesizes poly-N-acetyllactosamine, is dramatically upregulated in colon cancer. FEBS Lett. 579, 71-78. doi: 10.1016/j.febslet.2004.11.037

Ismail, R., Allaudin, Z. N., Abdullah, R., Mohd Lila, M. A., Nik Abd Rahman, N. M., and Abdul Rahman, S. O. (2016). Combination of VP3 and CD147-knockdown enhance apoptosis and tumor growth delay index in colorectal tumor allograft. BMC Cancer 16:461. doi: 10.1186/s12885-016-2530-8

Jiang, J. L., Zhou, Q., Yu, M. K., Ho, L. S., Chen, Z. N., and Chan, H. C. (2001). The involvement of HAb18G/CD147 in regulation of store-operated calcium entry and metastasis of human hepatoma cells. J. Biol. Chem. 276, 46870-46877. doi: 10.1074/jbc.M108291200

Jiang, Z., Ge, Y., Zhou, J., Xu, L., and Wu, S. L. (2010). Subcellular localization and tumor distribution of human beta3-galactosyltransferase by beta3GalT7 antiserum. Hybridoma 29, 141-146. doi: 10.1089/hyb.2009.0064

Jiang, Z., Hu, S., Hua, D., Ni, J., Xu, L., Ge, Y., et al. (2014). beta3GnT8 plays an important role in CD147 signal transduction as an upstream modulator of MMP production in tumor cells. Oncol. Rep. 32, 1156-1162. doi: 10.3892/or. 2014.3280

Kim, Y. S., Yoo, H. S., and Ko, J. H. (2009). Implication of aberrant glycosylation in cancer and use of lectin for cancer biomarker discovery. Protein Pept. Lett. 16, 499-507. doi: 10.2174/092986609788167798

Krishnan, V., Bane, S. M., Kawle, P. D., Naresh, K. N., and Kalraiya, R. D. (2005). Altered melanoma cell surface glycosylation mediates organ specific adhesion and metastasis via lectin receptors on the lung vascular endothelium. Clin. Exp. Metastasis 22, 11-24. doi: 10.1007/s10585-005-2036-2

Liu, J., Shen, L., Yang, L., Hu, S., Xu, L., and Wu, S. (2014). High expression of beta3GnT8 is associated with the metastatic potential of human glioma. Int. J. Mol. Med. 33, 1459-1468. doi: 10.3892/ijmm.2014.1736

Meany, D. L., and Chan, D. W. (2011). Aberrant glycosylation associated with enzymes as cancer biomarkers. Clin. Proteomics 8:7. doi: 10.1186/15590275-8-7

Nangia-Makker, P., Raz, T., Tait, L., Hogan, V., Fridman, R., and Raz, A. (2007). Galectin-3 cleavage: a novel surrogate marker for matrix metalloproteinase activity in growing breast cancers. Cancer Res. 67, 11760-11768. doi: 10.1158/ 0008-5472.CAN-07-3233
Ni, J., Jiang, Z., Shen, L., Gao, L., Yu, M., Xu, X., et al. (2014). beta3GnT8 regulates the metastatic potential of colorectal carcinoma cells by altering the glycosylation of CD147. Oncol. Rep. 31, 1795-1801. doi: 10.3892/or.2014. 3042

Ochieng, J., Fridman, R., Nangia-Makker, P., Kleiner, D. E., Liotta, L. A., Stetler-Stevenson, W. G., et al. (1994). Galectin-3 is a novel substrate for human matrix metalloproteinases-2 and -9. Biochemistry 33, 14109-14114. doi: 10.1021/bi00251a020

Pan, Y., He, B., Song, G., Bao, Q., Tang, Z., Tian, F., et al. (2012). CD147 silencing via RNA interference reduces tumor cell invasion, metastasis and increases chemosensitivity in pancreatic cancer cells. Oncol. Rep. 27, 2003-2009. doi: 10.3892/or.2012.1729

Polette, M., Gilles, C., Marchand, V., Lorenzato, M., Toole, B., Tournier, J. M., et al. (1997). Tumor collagenase stimulatory factor (TCSF) expression and localization in human lung and breast cancers. J. Histochem. Cytochem. 45, 703-709. doi: 10.1177/002215549704500508

Sameshima, T., Nabeshima, K., Toole, B. P., Yokogami, K., Okada, Y., Goya, T., et al. (2000). Expression of emmprin (CD147), a cell surface inducer of matrix metalloproteinases, in normal human brain and gliomas. Int. J. Cancer 88, 21-27. doi: 10.1002/1097-0215(20001001)88:1<21::AID-IJC4>3.0.CO;2-S

Seko, A., and Yamashita, K. (2005). Characterization of a novel galactose beta1,3-N-acetylglucosaminyltransferase (beta3Gn-T8): the complex formation of beta3Gn-T2 and beta3Gn-T8 enhances enzymatic activity. Glycobiology 15, 943-951. doi: 10.1093/glycob/cwi082

Seko, A., and Yamashita, K. (2008). Activation of beta1,3-Nacetylglucosaminyltransferase-2 (beta3Gn-T2) by beta3Gn-T8. Possible involvement of beta3Gn-T8 in increasing poly-N-acetyllactosamine chains in differentiated HL-60 cells. J. Biol. Chem. 283, 33094-33100. doi: 10.1074/jbc.M806933200

Shen, L., Dong, X., Yu, M., Luo, Z., and Wu, S. (2017). beta3GnT8 promotes gastric cancer invasion by regulating the glycosylation of CD147. J. Cancer 8, 314-322. doi: $10.7150 /$ jca. 16526

Siegel, R. L., Miller, K. D., and Jemal, A. (2017). Cancer statistics, 2017. CA Cancer J. Clin. 67, 7-30. doi: 10.3322/caac.21387

Sparrow, C. P., Leffler, H., and Barondes, S. H. (1987). Multiple soluble betagalactoside-binding lectins from human lung. J. Biol. Chem. 262, 7383-7390.

Sun, J., and Hemler, M. E. (2001). Regulation of MMP-1 and MMP-2 production through CD147/extracellular matrix metalloproteinase inducer interactions. Cancer Res. 61, 2276-2281.

Tang, W., Chang, S. B., and Hemler, M. E. (2004). Links between CD147 function, glycosylation, and caveolin-1. Mol. Biol. Cell 15, 4043-4050. doi: 10.1091/mbc. e04-05-0402

Togayachi, A., Kozono, Y., Kuno, A., Ohkura, T., Sato, T., Hirabayashi, J., et al. (2010). Beta3GnT2 (B3GNT2), a major polylactosamine synthase: analysis of B3GNT2-deficient mice. Methods Enzymol. 479, 185-204. doi: 10.1016/S00766879(10)79011-X

Yang, G., Tan, Z., Lu, W., Guo, J., Yu, H., Yu, J., et al. (2015). Quantitative glycome analysis of $\mathrm{N}$-glycan patterns in bladder cancer vs normal bladder cells using an integrated strategy. J. Proteome Res. 14, 639-653. doi: 10.1021/pr50 06026

Zhu, S., Chu, D., Zhang, Y., Wang, X., Gong, L., Han, X., et al. (2013). EMMPRIN/CD147 expression is associated with disease-free survival of patients with colorectal cancer. Med. Oncol. 30:369. doi: 10.1007/s12032-0120369-7

Conflict of Interest Statement: The authors declare that the research was conducted in the absence of any commercial or financial relationships that could be construed as a potential conflict of interest.

The reviewer XL and handling Editor declared their shared affiliation.

Copyright (c) 2018 Jiang, Zhang, Liu, Yin, Tong, Lv, Wei and Wu. This is an openaccess article distributed under the terms of the Creative Commons Attribution License (CC BY). The use, distribution or reproduction in other forums is permitted, provided the original author(s) and the copyright owner are credited and that the original publication in this journal is cited, in accordance with accepted academic practice. No use, distribution or reproduction is permitted which does not comply with these terms. 